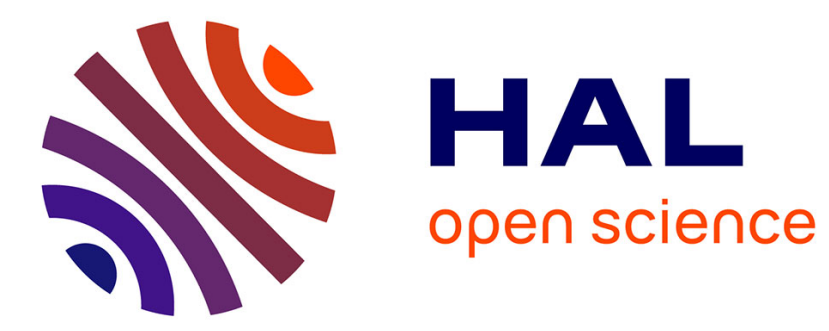

\title{
Sources and transport of suspended calcites in Pacific Deep Water
}

\author{
J. Brun-Cottan, R. Auger, C. Lambere, R. Chesselet
}

\section{To cite this version:}

J. Brun-Cottan, R. Auger, C. Lambere, R. Chesselet. Sources and transport of suspended calcites in Pacific Deep Water. Journal of marine research, 1991, 49 (3), pp.543-564. 10.1357/002224091784995837 . hal-03582682

\section{HAL Id: hal-03582682 \\ https://hal.science/hal-03582682}

Submitted on 21 Feb 2022

HAL is a multi-disciplinary open access archive for the deposit and dissemination of scientific research documents, whether they are published or not. The documents may come from teaching and research institutions in France or abroad, or from public or private research centers.
L'archive ouverte pluridisciplinaire HAL, est destinée au dépôt et à la diffusion de documents scientifiques de niveau recherche, publiés ou non, émanant des établissements d'enseignement et de recherche français ou étrangers, des laboratoires publics ou privés. 


\title{
Sources and transport of suspended calcites in Pacific Deep Water
}

\author{
by J. C. Brun-Cottan, ${ }^{1}$ R. Auger, ${ }^{2}$ C. E. Lambert ${ }^{2}$ and R. Chesselet ${ }^{2}$
}

\begin{abstract}
Significantly large concentrations of suspended matter, especially calcites, are found at some locations in the Deep Pacific, particularly at the depth of the Pacific Benthic Thermocline. These particle-rich layers cannot be explained by simple classical settling processes nor by resuspension of the underlying sediment. A theoretical approach based on these data, on the hydrodynamic characteristics of the regional circulation and on some known physical and chemical parameters, leads us to postulate two possible mechanisms: the settling of large particles from surface waters and their preferential disaggregation at some specific depth, particularly at the Pacific Benthic Thermocline depth; or alternatively, the resuspension at those depths of old calcareous sediments from the flanks of East Pacific Rise associated with a horizontal advective diffusive transport mechanism. New chemical and electron-microscope analyses of GEOSECS samples give rise to the conclusion that the resuspension mechanism is the most probable. A simple model based on this mechanism, using our calcite concentrations at the PBT depth implies that the calcium carbonate flux arising from this source ranges between $5 \times 10^{6}$ and $5 \times 10^{8}$ tons per year. The erosion intensity and the quantity of calcium carbonate contained by the rises or the seamounts, must be large enough to maintain this flux. Those two constraints have been successfully tested.
\end{abstract}

\section{Introduction}

Concentrations of Total Suspended Matter (TSM) in the Deep Pacific Ocean generally vary between $10-20 \mu \mathrm{g} \mathrm{kg}^{-1}$ with a frequent lack of calcites below $3 \mathrm{~km}$ depth. However, in the deep waters of the region where the Pacific Benthic Thermocline (PBT) is present (GEOSECS st. 235, 239 and 306) (Fig. 1), there are layers of higher concentrations of TSM (Fig. 2) and calcites (Fig. 3). The PBT is the interface between deep Pacific waters moving southward and Antarctic waters moving northward, it was first described by Craig et al. (1972) as the "Benthic Front." The PBT area has special interest for the following reasons:

- The particle-rich layers found in this area, in terms of bulk concentration or calcite concentrations, represent a heterogeneity in the water column, they are found far above the bottom (GEOSECS, 1974; Bainbridge et al., 1976, 1977)

2. Centre des Faibles Radioactivités (CNRS-CEA), 91198 Gif/Yvette France. 


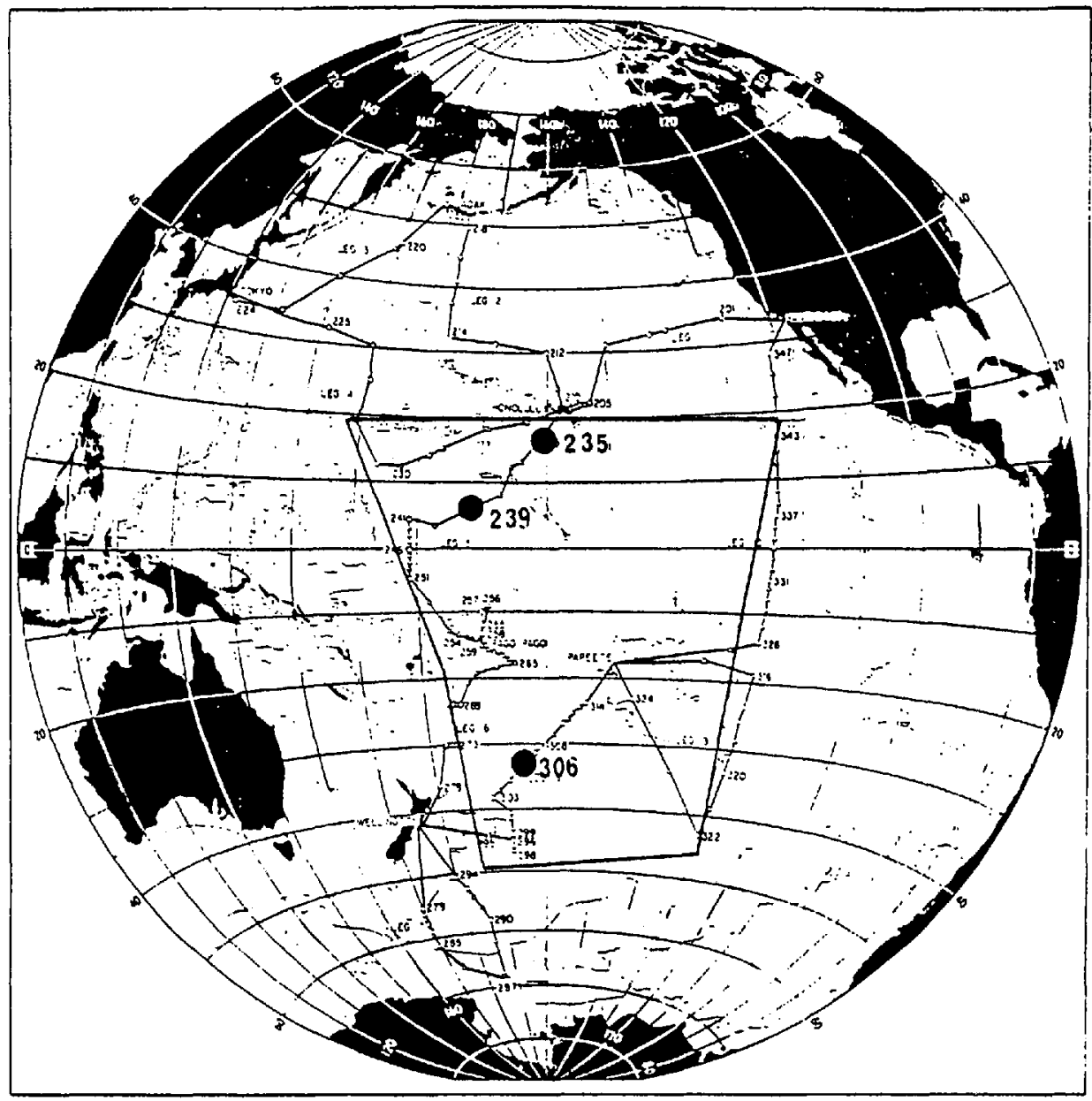

Figure 1. Schematic location of the PBT and coordinates of the three GEOSECS stations where calcites have been measured by CFR laboratory.

where the bottom current velocity is small. These layers are vertically squeezed between clear water layers. This is different from the Atlantic Ocean situation, where the vertical distribution of TSM exhibits a surface maximum due to biological processes, a deep maximum caused by vertical resuspension of underlying sediment due to high bottom current velocities (Brewer et al., 1976) and a "clear water minimum" at mid-water, which corresponds to an oceanic background of suspended particles (Biscaye and Eittreim, 1974, 1977; Eittreim and Ewing, 1976).

- The PBT is largely below the lysocline. However, particles exhibit high calcite concentrations as shown by microscopy (Honjo, 1975) and chemical analyses (Krishnaswami et al., 1976). 
The PBT area, then, exhibits vertical discrete peaks of particles at many depths and especially a large amount of calcites inside a few-hundred-meter thick layer at the PBT depth. Classical mechanisms describing the presence of suspended particles in deep waters cannot be used to describe these observations. In this paper, the different possible input sources and mechanisms leading to the presence of discrete layers of particles, conservative or nonconservative (as calcites), and their transport mechanisms will be analyzed and discussed.

\section{Materials and methods}

The filtration procedure is described elsewhere (Brewer et al., 1976). TSM has been weighted at LDGO and WHOI. Incomplete rinsing of the Nuclepore filters on board can induce the presence of gypsum by recrystalliation of residual salts, therefore contaminating the filters analyzed for total calcium. Preliminary examination by scanning electron microscopy combined with electron microprobe (SEMEMP) and further experiments (Aubey, 1977) showed that such contamination may represent up to $100 \%$ of total calcium present on the filter. Thus, all the filters analyzed were rinsed two times with $25 \mathrm{ml}$ of Milli-Q water to eliminate gypsum. This second rinsing must be fast to avoid the dissolution of small particles of calcium carbonate. Validity of the procedure was checked by examining a portion of each filter by SEM-EMP.

Filters were then rinsed with low acidic solutions to recover the calcium from the calcites. Analyses of calcium were completed by atomic absorption spectrometry.

\section{Results}

\section{a. Total suspended particulate matter}

In intermediate and deep waters of the PBT area, TSM does not present a monotonous decrease with depth but, in most cases, shows some maxima detected in 200 to $300 \mathrm{~m}$ thick layers. A list of these TSM maxima is presented Table 1. This Table was made from GEOSECS Pacific TSM data (GEOSECS, 1974). For each of the GEOSECS profiles we studied, about 40 TSM samples were taken at $100-200 \mathrm{~m}$ intervals. Such a resolution allowed sampling of the narrow zones of high concentrations. Some layers, containing large amounts of aluminosilicate materials, demonstrated TSM concentrations over $100 \mu \mathrm{g} \mathrm{I^{-1 }}$, more than the background level of 10-20 $\mu \mathrm{g} \mathrm{l}^{-1}$ (Fig. 2).

\section{b. Biogenic calcite}

Water layers containing calcite appear mainly at the PBT depth (Fig. 3) at the three GEOSECS stations examined in this paper (see locations in Table 1). SEMEMP analyses demonstrated that calcites in these layers come from coccolithophorids and their debris. No other species were identifiable on the filters. As seen in 
Table 1. The total mass and depth of samples with particle mass concentration greater than 2 times the background, is indicated for all Pacific GEOSECS stations below $1 \mathrm{~km}$. The far right column shows the total number of samples collected below $1 \mathrm{~km}$. The general background of $15 \mu \mathrm{g} \mathrm{I}^{-1}$ is based on the measurements made by Woods Hole Oceanographic Institution, the background we measured on the 3 Stations studied here in detail is about $25 \mu \mathrm{g} \mathrm{I}^{-1}$. Data from Bainbridge et al., 1977.

\begin{tabular}{|c|c|c|c|c|c|}
\hline Station & Latitude & Longitude & $\begin{array}{l}\text { Depth } \\
\text { (m) }\end{array}$ & $\begin{array}{c}\text { Concentration } \\
\left(\mu \mathrm{g} \mathrm{l}^{-1}\right)\end{array}$ & $\begin{array}{c}\text { Number of } \\
\text { Samples } \\
\text { below } 1 \mathrm{~km}\end{array}$ \\
\hline 201 & $34.1 \mathrm{~N}$ & $127.6 \mathrm{~W}$ & $\begin{array}{l}1641 \\
3914\end{array}$ & $\begin{array}{l}85 \\
51\end{array}$ & 28 \\
\hline \multirow[t]{4}{*}{225} & $32.3 \mathrm{~N}$ & $161.5 \mathrm{~W}$ & 2068 & 41 & \multirow{4}{*}{26} \\
\hline & & & 2964 & 33 & \\
\hline & & & 3548 & 39 & \\
\hline & & & 4927 & 31 & \\
\hline \multirow[t]{3}{*}{269} & $23.6 \mathrm{~S}$ & $174.3 \mathrm{~W}$ & 1146 & 39 & \multirow{3}{*}{19} \\
\hline & & & 1291 & 30 & \\
\hline & & & 3438 & 31 & \\
\hline \multirow[t]{3}{*}{282} & $57.3 \mathrm{~S}$ & $169.4 \mathrm{E}$ & 2640 & 30 & \multirow{3}{*}{15} \\
\hline & & & 4736 & 54 & \\
\hline & & & 5157 & 41 & \\
\hline 287 & $69.5 \mathrm{~S}$ & $173.3 \mathrm{~W}$ & 4042 & 60 & 26 \\
\hline \multirow[t]{3}{*}{296} & $44.6 \mathrm{~S}$ & $166.4 \mathrm{~W}$ & 2072 & 42 & \multirow{3}{*}{33} \\
\hline & & & 4431 & 30 & \\
\hline & & & 4580 & 51 & \\
\hline 306 & $32.5 \mathrm{~S}$ & $163.4 \mathrm{~W}$ & 3773 & 43 & \multirow[t]{2}{*}{20} \\
\hline \multirow[t]{3}{*}{317} & $23.4 \mathrm{~S}$ & $127.1 \mathrm{~W}$ & 1288 & 30 & \\
\hline & & & 2354 & 30 & \multirow[t]{2}{*}{19} \\
\hline & & & 3259 & 31 & \\
\hline \multirow[t]{3}{*}{326} & $14.3 \mathrm{~S}$ & $126.1 \mathrm{~W}$ & 1092 & 37 & \multirow{3}{*}{10} \\
\hline & & & 1394 & 30 & \\
\hline & & & 1543 & 62 & \\
\hline \multirow[t]{6}{*}{331} & $4.4 \mathrm{~S}$ & $125.8 \mathrm{~W}$ & 2432 & 36 & \multirow{6}{*}{16} \\
\hline & & & 3096 & 35 & \\
\hline & & & 3544 & 30 & \\
\hline & & & 3771 & 36 & \\
\hline & & & 3996 & 36 & \\
\hline & & & 4298 & 31 & \\
\hline \multirow[t]{2}{*}{337} & $4.5 \mathrm{~N}$ & $124.5 \mathrm{~W}$ & 1327 & 33 & \multirow{2}{*}{19} \\
\hline & & & 1618 & 31 & \\
\hline \multirow[t]{2}{*}{343} & $16.3 \mathrm{~N}$ & $123.1 \mathrm{~W}$ & 1774 & 31 & \multirow{2}{*}{11} \\
\hline & & & 2769 & 36 & \\
\hline
\end{tabular}




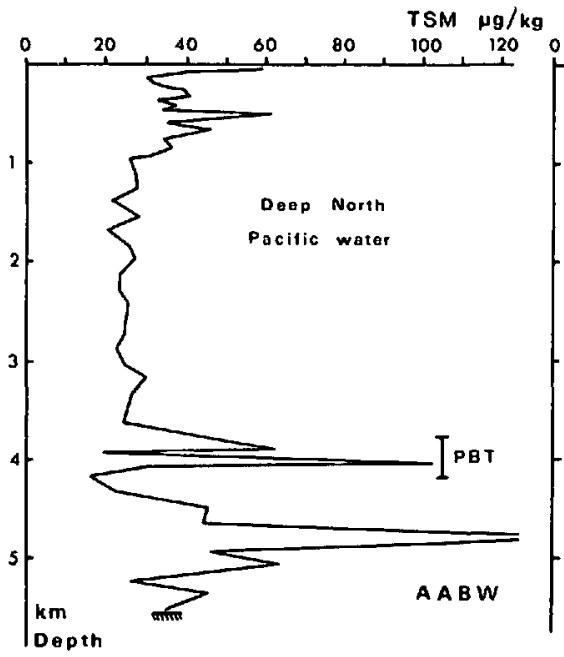

station 235

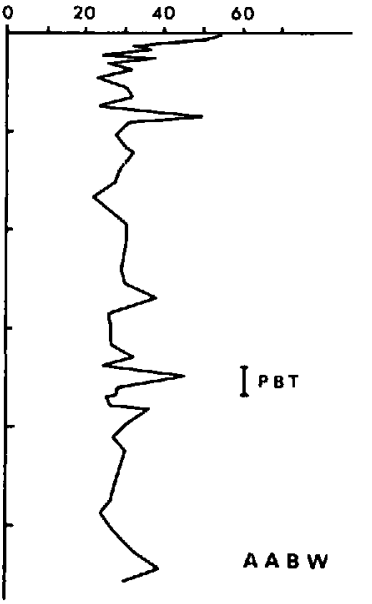

station 239

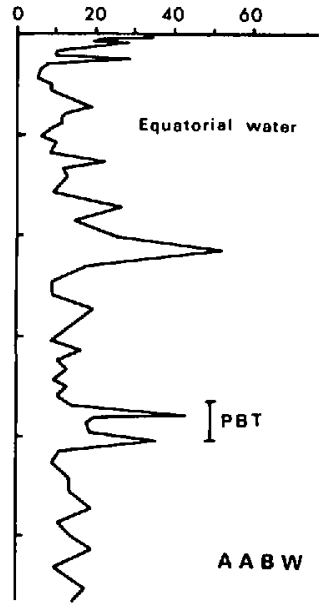

station 306

Figure 2. Vertical distribution of the total suspended mass concentration at GEOSECS stations: 235,239 and 306.

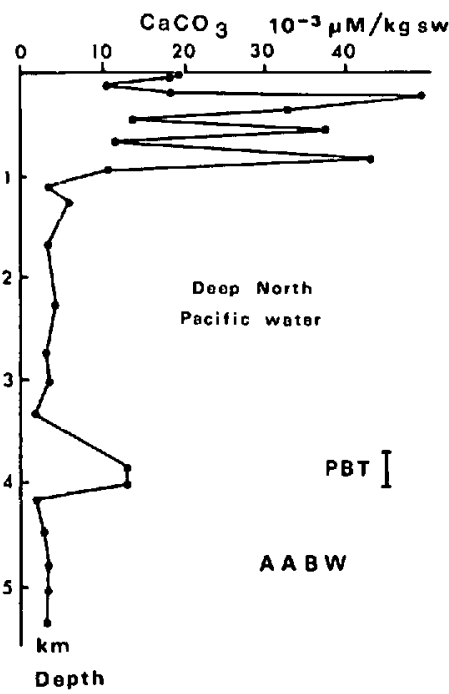

station 235

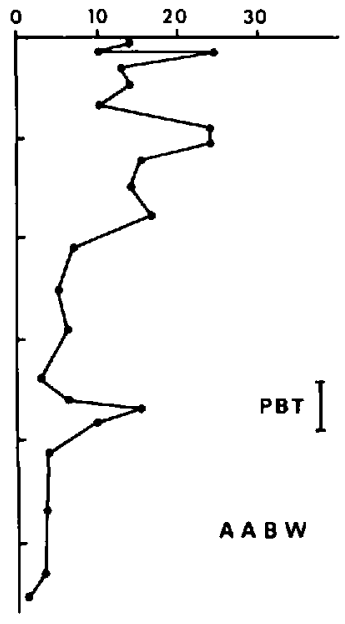

station 239

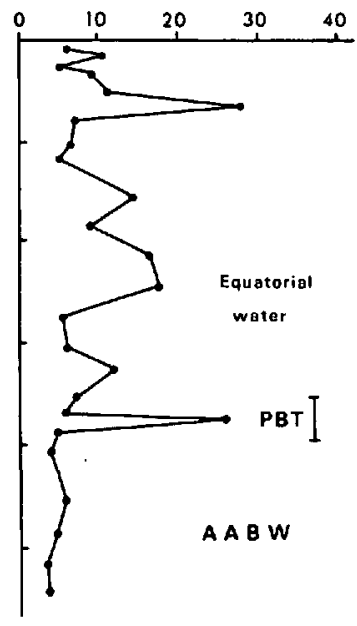

station 300

Figure 3. Vertical distribution of the calcium carbonate at the 3 GEOSECS stations (The uncertainty on the measured values is less than $10^{-3} \mu \mathrm{M} \mathrm{kg}^{-1} \mathrm{sw}$.) 
Figures 4 and 5, a large fraction of the coccoliths sampled at the PBT depth was still intact, whereas above or below the PBT, where lower concentrations of calcite are seen, large dissolution of coccolith fragments was apparent.

The high concentrations of calcium given by atomic absorption are confirmed by the SEM-EMP examination.

The variations in saturation index for calcium carbonate at the PBT depth compared to other measurements in natural environment are too small to represent a significant signal of $\mathrm{CaCO}_{3}$ dissolution.

\section{Determination of particles sources and transport models}

What are the mechanisms that generate and control the presence of TSM and calcite maxima in deep waters in the PBT area? To answer this question, we will determine and analyze all the possible mechanisms of vertical and horizontal input which can be involved in the Pacific environment. We will then test the most probable ones with simple physical models. These mechanisms are schematically presented in Figure 6.

\section{a. Vertical input mechanisms}

The vertical mechanisms could be divided into resuspension processes and settling processes from the surface waters.

i. Vertical input by resuspension. The concentration profile of TSM given by resuspension from the sea floor is exponential at steady state. This kind of profile is not observed in this region of the Pacific Ocean. Only at station 235 (Fig. 2) a peak of TSM at $4600 \mathrm{~m}$ depth could be due to a resuspension mechanism but it would involve a non steady state process (Perigaud et al., 1982) and would necessarily have a very local extension. Moreover this peak does not contain high calcite concentration. Indeed, sea floor at these depths is free of calcite.

ii. Vertical settling transport of particles. Downward transport of particles is accomplished either through slow settling of small individual particles or through incorporation of small particles in aggregates with high settling velocities. These modes of vertical transport are analyzed below to determine if they can account for TSM and calcite layers observed in the water column.

iii. Small particles settling. The sedimentation of small particles at steady state is inconsistent with the presence of isolated layers within water masses otherwise poor in suspended matter (Fig. 2 and 3). Moreover, within the calcite-rich layers, intact coccoliths coexist with coccolith debris. These debris are smaller and therefore are associated with a smaller settling velocity. Vertical settling is unlikely to concentrate 

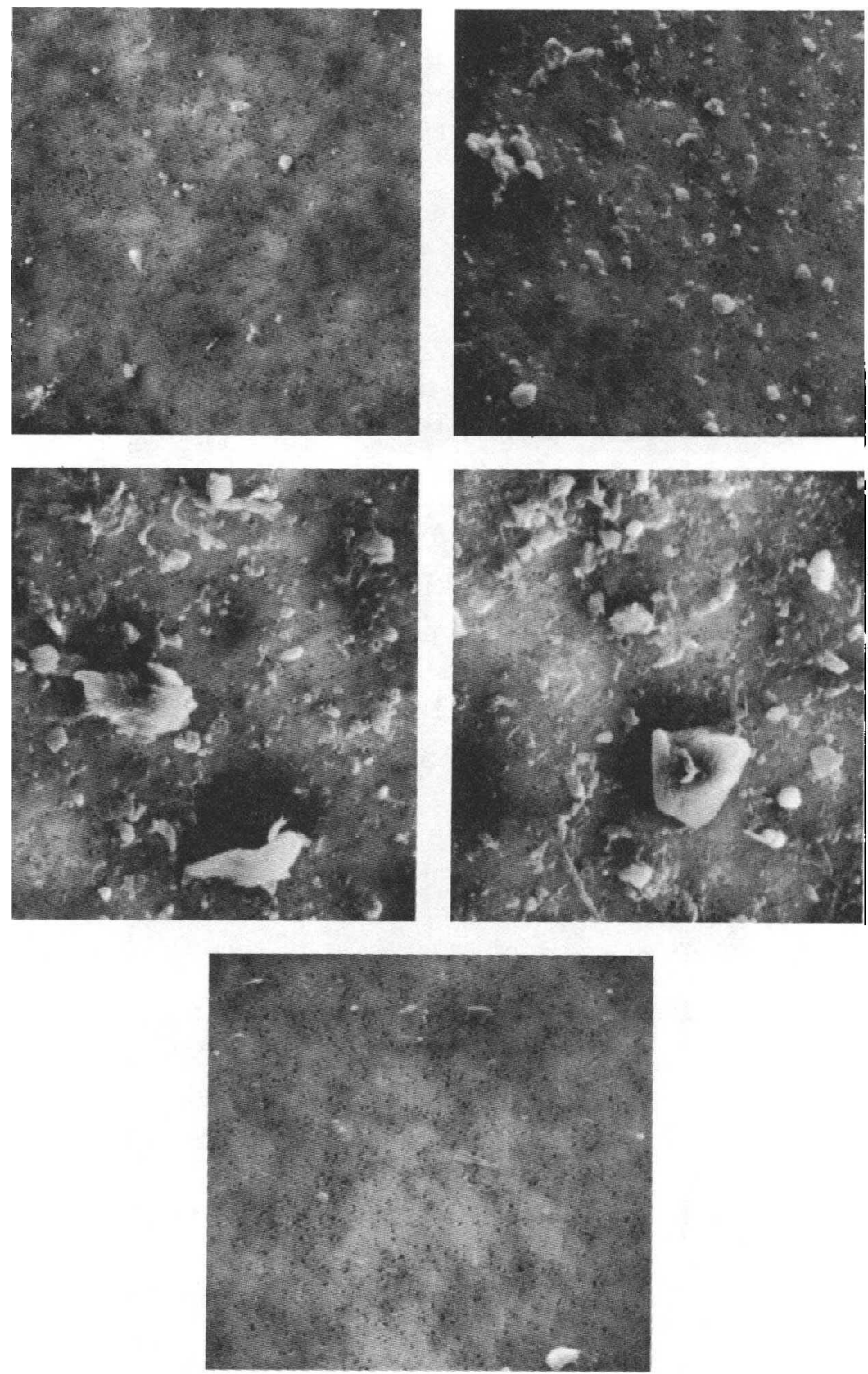

Figure 4. Electron microscope pictures of filtered particles ( $\times 1000$ magnification) on Nuclepore filters at GEOSECS station 306. Filters one, two and five are from water above and below the PBT; filters three and four are from water at the PBT depth. As all pictures are on the same scale, it can be seen readily that filters three and four are highly enriched in particles, compared to samples above and below. 

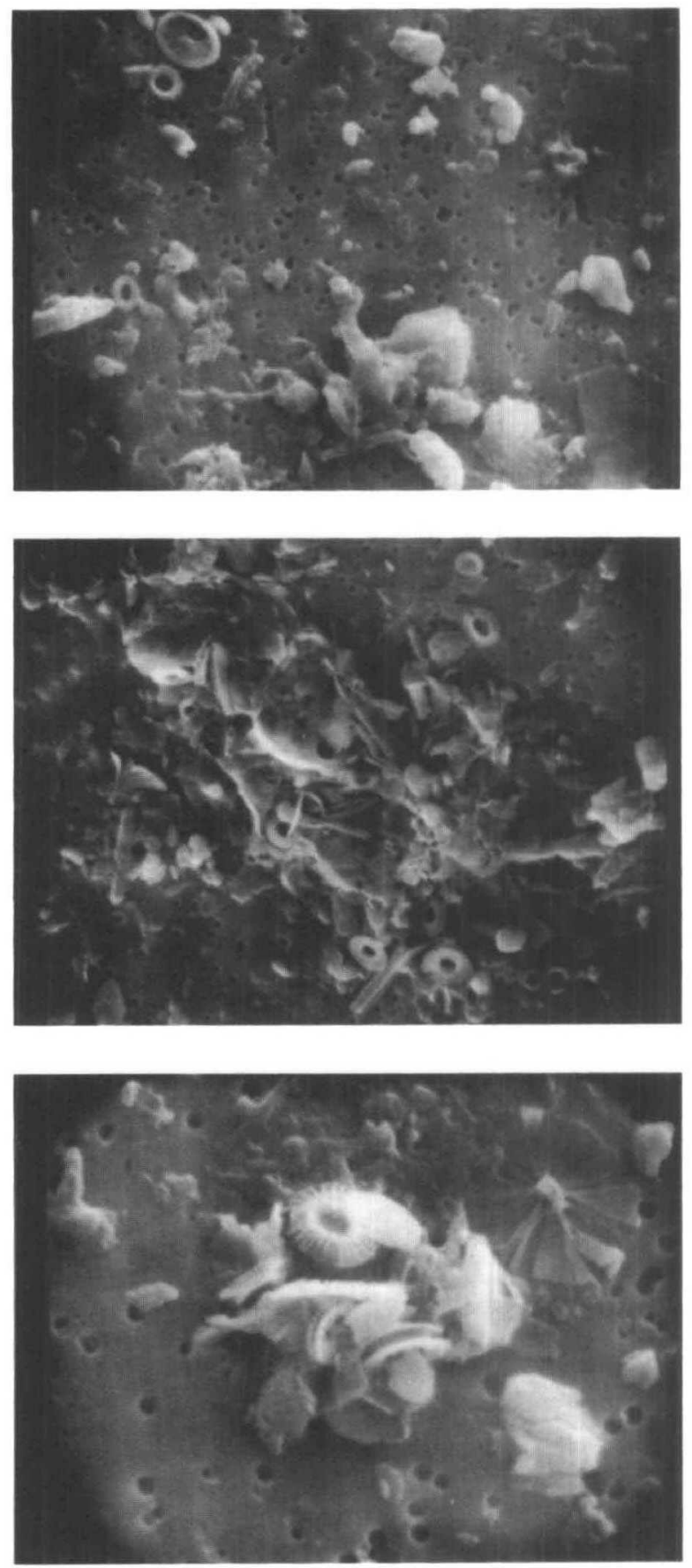

Figure 5. Detailed views of filters three ( $\times 3000$ magnification) and four $(\times 7500$ magnification). These samples mainly comprise coccoliths and silicate debris as well as clay particles. Some foraminifera were observed but no other calcite crystals. 


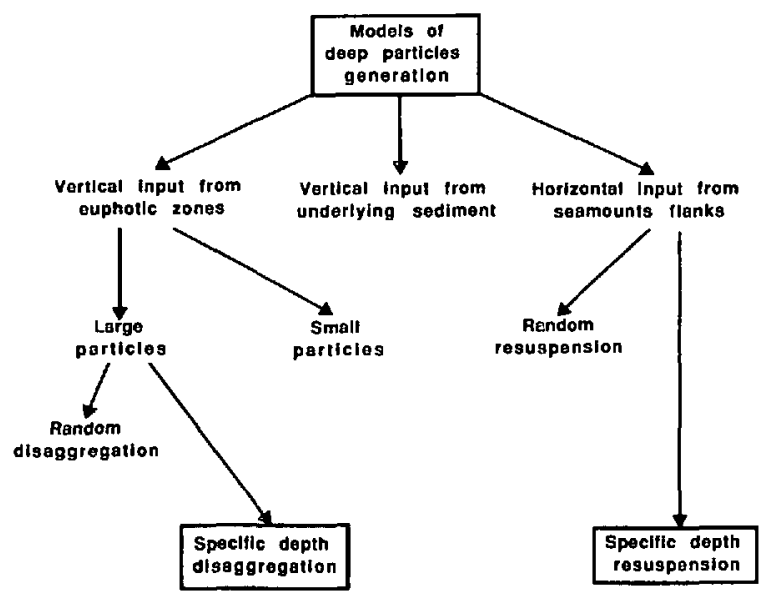

Figure 6. Block diagram of the research pattern used in this study to identify the most adequate models allowing the presence of layers of insoluble and soluble particles in the PBT.

such a heterogenous group. Therefore, the vertical discrete and high concentration of calcite is not explained by slow sinking of small particles.

iv. Large particles settling and random disaggregation. Let us suppose that the mineral fraction is included in large fecal material subjected to disintegration in the water column. Many workers, specifically the VERTEX group in the Pacific, have shown, using sediment traps, that the mass flux of particles is transported from surface waters to the sediment within a few weeks. This short residence time in the water column is valid for coccoliths and other calcite particles as shown by Honjo, 1984. Honjo first found free coccoliths in undersaturated deep Pacific water columns in 1975 (Honjo, 1975, 1976). To explain this, he hypothesized a rapid transport by fecal pellet. He explained the "fresh look" of suspended coccoliths in deep waters by a steady state model of repeated spillage and scavenging of particles from the host aggregates. A random distribution hypothesis is described in Honjo, 1975. It is the first attempt to explain a continuous vertical distribution of small particles of calcite in the water column. However, if random disintegration of large particles occurs, the mass concentration of particles then decreases exponentially with depth and does not show any maximum in concentration. The only way to explain a vertical local increase of TSM concentration is by a variation of the particle settling velocity. In the case of large particles having a disaggregation rate constant with time, the concentration of these particles must increase when the settling velocity decreases in a given layer because they have a longer residence time in this layer (Fig. 7a). It implies that the flux of the small particles produced by the disaggregation of the large particles also increases. A slow-down of the settling velocity can only be due to the decrease of 


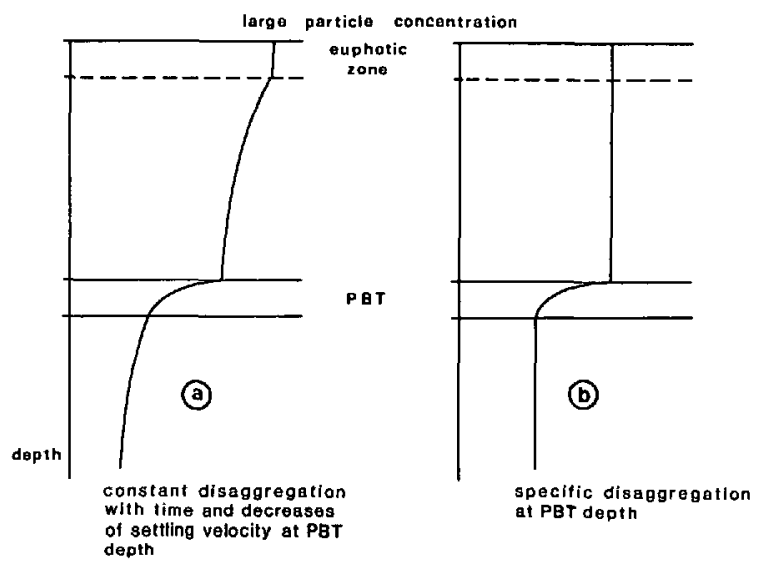

Figure 7. Vertical settling model where the PBT layer is supplied in calcites by the disaggregation of large particles or aggregates falling from the surface waters. (a) The disaggregation rate of the settling particles is constant with time; it varies with depth if the particle settling velocity varies, as shown for PBT depth. (b) The disaggregation rate is considered to be zero above and below the PBT and constant in the PBT waters.

the density ratio between large particles and the surrounding water and to the increase of the water viscosity. We therefore analyze the temperature and salinity variations at the PBT depth, as shown by the CTD records, to study whether they are sufficient to provide a sufficient decrease of the settling velocity.

The calcite concentration maximum at the PBT depth, over the background concentration, is of the order of four, this increase implies that the settling velocity slows down by a factor of two, for the following reasons:

- At steady state, the large particles concentration is inversely proportional to the settling velocity (Brun-Cottan, 1976).

- The residence time of large particles doubles in this water, therefore the production of small particles, due to the breakage of the large particles, doubles.

A decrease of the particle settling velocity of two implies that the relative density $\delta \rho$ between the particle and the surrounding water is divided by two.

A large particle can be considered as made up of two parts: a mineral fraction of invariant density and an organic hydrated fraction with a density close to that of the water surrounding the particle. In deep waters, water density variations are mainly due to changes in temperature, the density variation of the water surrounding the particle is therefore the same as that of the density of the sea water; this implies that the $\delta \rho$ variations fully depends on the proportion of the mineral fraction of the particle. Taking the water densities from the GEOSECS data and assuming that the mineral density is 2.4 (as is calcite), we can calculate the mineral fraction of the 
particle which is necessary to obtain a $\delta \rho$ divided by two. This calculated mineral fraction must be less than $0.001 \%$ of the total particle mass, a value much lower than those usually observed or calculated from particle size distribution data associated with particle mass determinations (McCave, 1975; Brun-Cottan, 1976; Bishop et al., 1980; Lambert et al., 1981; Jedwab, 1980). The vertical $\delta \rho$ in the PBT layer is therefore too small to account for the expected decrease of the particle settling velocity.

v. Preferential disaggregation depth. What is the concentration profile if the disaggregation rate of large particles varies? To answer this question in a simple way, we propose a model of vertical transport of calcite by the settling of fecal pellets or aggregates in which we assume that large particles stay intact during their fall through the water column, except when they reach some preferential depth, as the PBT one, where their disaggregation occur (Fig. 7b). This model implies a breakage mechanism such as high turbulent energy at this depth. We found that waters at the PBT depth contain large amounts of entire coccoliths. Calcite particles at the PBT depth are dissolved at a rate $\lambda$ which is related to the half dissolution time $\tau$, by $\lambda=$ $-\operatorname{Ln}(2) / \tau$. We can assume that $\tau$ is between two months and two years (Berger, 1967; Honjo and Erez, 1978). The PBT spreads vertically in a depth interval of approximately $400 \mathrm{~m}$. Therefore the standing crop of calcite is about $4 \times 10^{-5} \mathrm{~g} \mathrm{~cm}^{-2}$. To maintain this standing crop for $\tau$ varying between two months and two years, the flux of calcite from surface waters should be comprised of between 4 and $24 \times 10^{-5} \mathrm{~g} \mathrm{~cm}^{-2}$ year $^{-1}$. The productivity of the surface waters could therefore provide the observed concentration of calcite.

\section{b. Lateral resuspension from rises or seamounts}

The shear effect of water on the flanks of rises or seamounts can induce resuspension of sediments. This mechanism has been first described by Eittreim and Ewing (1976) for resuspension in the benthic boundary layer (BBL). Resuspension along rise or seamount flanks could be either homogeneous within a large water mass, or could occur at preferential depths such as the PBT. These two possibilities will be discussed as a function of the physical and geochemical constraints of the system.

Whatever the mechanism invoked, we start the model with a point source input generating successive resuspensions of a quantity $Q$ of particles (Fig. 8). The concentration $C$ of particles in the one dimensional space $x$, given by one resuspension event (puff) at time $t$ is defined by:

$$
C=\frac{Q}{\sqrt{2 \pi} \sigma} \exp -\frac{x^{2}}{2 \sigma^{2}}
$$

where $\sigma^{2}=2 k x t$ is the quadratic dispersion at time $t$. 


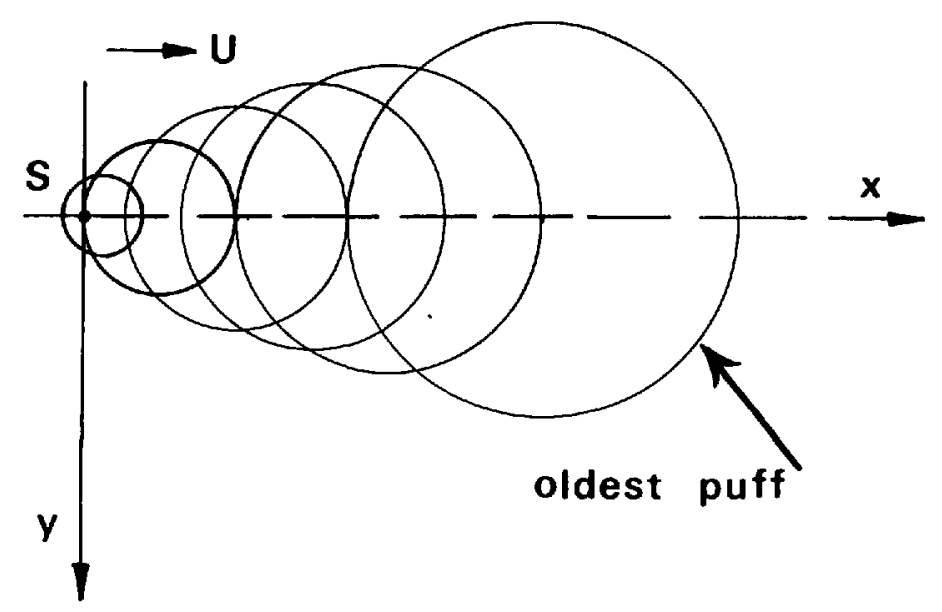

Figure 8. Sketch of a point source in the water emitting successive puffs of particles. For insoluble particles, the amount of each puff is constant with time. For soluble particles, the amount of each puff decreases following a given dissolution law. A continuous source can be considered as well, the lag time between puffs vanishing.

i. General solutions for three dimensional space. For particle source located at the PBT depth, we must consider three-dimensional space where the time and space scales allow the application of steady state conditions. We also assume that the eddy viscosity coefficients $K x, K y$ and $K z$ are constant. Resuspended particles are either insoluble, such as clay particles, or soluble, as calcite particles.

ii. Insoluble particles. With a point source in a three dimensional space, emitting particles at rate $q$, at time $t^{\prime}$ during a time interval $d t^{\prime}$ in a water mass moving with a velocity $u$ in the horizontal direction $x$, the mass concentration $C(x, y, z, t)$ at fixed time $t$, is given, following Frenkiel (1953) and Csanady (1980) as:

$$
\begin{gathered}
d C=\frac{q d t^{\prime}}{8 \sqrt[3]{\pi} \sqrt{K_{x} K_{y} K_{z}} \sqrt[3]{t-t^{\prime}}} \exp -\left[\frac{\left.\mid X-U\left(t-t^{\prime}\right)^{2}\right\}+Y^{2}+Z^{2}}{4\left(t-t^{\prime}\right)}\right] \\
\text { with } X^{2}=\frac{x^{2}}{K_{x}}, \quad Y^{2}=\frac{y^{2}}{K_{y}}, \quad Z^{2}=\frac{z^{2}}{K_{z}} \quad \text { and } \quad U^{2}=\frac{u^{2}}{K_{x}} .
\end{gathered}
$$

By integrating all the puffs having ages from $-\infty$ to $t$, using Frenkiel (1953) and Gradshteyn and Ryzhik (1980), one can calculate the mass concentration $C(x, y, z, t)=\int d C$ which is finally independent of time:

$$
C=\frac{q}{4 \pi \sqrt{K_{x} K_{y} K_{z}} R} \exp -\frac{1}{2} U(R-X)
$$


with

$$
R^{2}=X^{2}+Y^{2}+Z^{2}
$$

Far away from the source, the amount of particles contained in slices of water perpendicular to $x$, with a thickness $\delta x$, is independent of $x$ ( $\delta x \iint C d y d z=$ constant $)$, (Csanady, 1980). This means that the effect of the mixing term $K x$ along the $x$ axis, on the mass concentration, can be discarded. This implies that in a one dimensional space, the mass concentration $C(x)$ is independent of turbulent mixing:

$$
C=q / u \text {. }
$$

This result can be visualized as a pipe with a permanent flow, in which there is a continuous and homogeneous particle injection in a surface area perpendicular to the pipe.

iii. Soluble particles. One can assume that each puff dissolves following a simple $\exp (-\lambda t)$ law, where $\lambda$ is the dissolution coefficient of the particles. With Eq. (2) and setting $\alpha=t-t^{\prime}$, one obtain:

$$
C=\int_{0}^{\infty} \frac{q \exp -(\lambda \alpha) d \alpha}{8 \sqrt[3]{\pi} \sqrt{K_{x} K_{y} K_{z}} \sqrt[3]{\alpha}} \exp -\left[\frac{\left[X-U(\alpha)^{2}\right]+Y^{2}+Z^{2}}{4 \alpha}\right] .
$$

Integration by the method of Gradshteyn and Ryzhik (1980) yields

$$
C=\frac{q}{4 \pi \sqrt{K_{x} K_{y} K_{z}} R} \exp -\frac{1}{2}\left[R \sqrt{U^{2}+4 \lambda}-X U\right] .
$$

Contrary to the hypothesis developed in Section $4 \mathrm{~b}$ (ii), the mass concentration of soluble particles thus depends on the distance $x$, the mixing and the dissolution coefficient rate. In the case of a one dimensional space $x, C(x)$ becomes:

$$
C=\frac{q}{v} \exp -\left[\frac{x}{2 K_{x}}(v-u)\right]
$$

with

$$
v=\sqrt{u^{2}+4 \lambda K_{x}} .
$$

iv. Simplification for application in nature. If the particle source is composed by a pattern of many point sources, for an observer far away from these points, the resuspension events can be considered either as a point source or as a horizontal extended line source. 
v. Point source. In this case, if other sources exist, it is assumed that they are far enough from the observer to have a negligible effect on the observed particle concentration. For nondissolving particles, the maximum concentration at a reasonably long distance $x$ from the source, on the axis of the plume, is:

$$
C=\frac{q}{4 \pi \sqrt{K_{x} K_{y}} x}
$$

and for soluble particles, it is:

$$
C=\frac{q}{4 \pi K_{x} x} \exp -\frac{1}{2} \frac{x}{K_{x}}\left[\sqrt{u^{2}+4 \lambda K_{x}}-u\right] .
$$

Eqs. 8 and 9 clearly show that the concentration is very sensitive to the distance between the source and the sampling station. Because we do not know this distance, the model does not allow us in this case, to obtain quantitative data.

vi. Horizontal extended line source. Here, a random distribution of inputs, far away from the observer, is assumed. This is coherent with the spatial distribution of seamounts or rises in the Pacific; then the source can be regarded as a continuous line, with a quasi-infinite length, along direction $y$ perpendicular to the flow direction $x$. Therefore, the one-dimensional solutions (4) and (7) can be applied.

For insoluble particles, the concentration given by (4) is theoretically constant in all the PBT zone, whatever the distance $x$ from the source.

For soluble particles, the concentration given by (7) depends on $x, K x$ and the dissolution constant $\lambda$.

The case of an extended line source defines an ideal and simplistic structure. The major approximation stems from our ignorance of the actual distances to the sources from the collecting stations. Depending on these distances, the real situation is probably some combination of the two idealized cases: point and line sources. Considering the insufficient knowledge we have of the dynamics at the scales of the model, the line source model is the only one which allows a computation of the minimum resuspension flux needed to explain the measured particle concentration $C$. This flux is defined as $q / s$, where $s$ is a unit of vertical surface area perpendicular to the direction flow.

\section{Application and discussion of the lateral resuspension model}

The Pacific waters moving southward and the Antarctic waters moving northward have differential velocities on the order of a few $\mathrm{cm} \mathrm{s}^{-1}$ (Stommel and Arons, 1960; Johnson, 1972). Over the several hundred meters of the PBT width, the eddy diffusion coefficients could be very high, due to the friction between the two water masses. Indeed, at this interface, the instantaneous velocity along the rise or 
seamount flanks, induced by internal waves and burst, can be much higher than in the rest of the water column. In order to apply the deep input and transport model to the natural conditions encountered in this region of the Pacific Ocean, we set the following general assumptions:

- There is an extended horizontal input source.

-- The possible source lines are very scattered, looking at the map of the region.

Thus, precise determination of the distances from these sources to the studied stations is impossible. To run the model, we consider two distance lengths from the source line to the sampling points having reasonable meaning; they are set to $500 \mathrm{~km}$ and $1000 \mathrm{~km}$.

- The direction $x$ and the velocity $u$ correspond to the relative motion of the two water masses.

- The PBT layer is well mixed on the $z$ axis, then the $K z$ term is discarded.

- The settling velocity of the suspended particles is neglected, because of the time scale of the model, which is of the order of some months.

Because of the lack of precise values of the flow velocity $u$ and the horizontal mixing terms $K x$ and $K y$, in the PBT area, we run the model within the numerical field in which these physical parameters can reasonably lie:

-. The velocity $u$ varies from 1 to $10 \mathrm{~cm} \mathrm{~s}^{-1}$.

- The horizontal eddy diffusivity is considered isotropic $(K x=K y)$ and varies between $10^{4} \mathrm{~cm}^{2} \mathrm{~s}^{-1}$ and $10^{8} \mathrm{~cm}^{2} \mathrm{~s}^{-1}$. The first value, which is a minimum, applies to the stratified waters below and above the PBT. The second value is very high but consistent with very turbulent water (Freeland et al., 1975); it is considered as the maximum value for highly mixed water within the PBT layer.

In this application, we still need to define the resuspension mechanisms at the space scale of the water column. Two main processes can logically be taken into account (Fig. 6):

- random resuspension along the flanks of the rises.

-- preferential resuspension at given depths.

These two mechanisms (Fig. 9) can apply to the resuspension and the transport of insoluble and soluble particles.

\section{a. Resuspension at random depths}

i. Case of insoluble particles. The model applies to TSM concentrations observed in a resuspended plume far away from the source and poor in calcite. For example, the 

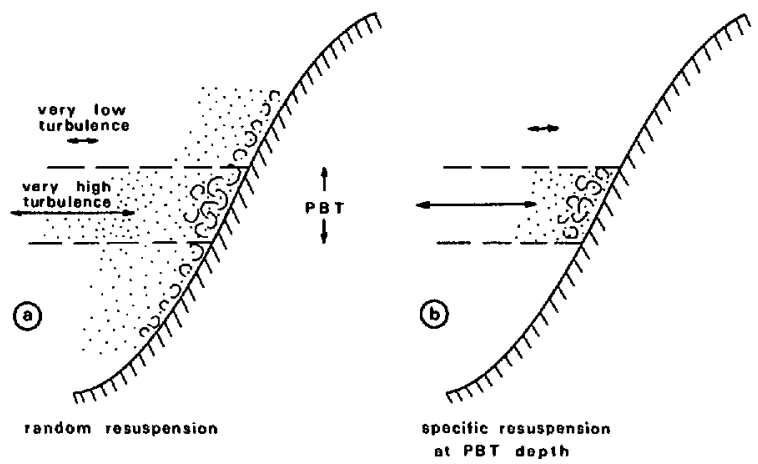

Figure 9. Model where the observed particle layers, such as the calcite high concentration at the PBT depth, come from resuspension processes along the rise flanks. (a) The resuspension process randomly occurs along the rise or seamount flanks. (b) The particle sources occur at specific depths, such as the PBT.

layer of particles with a concentration of $100 \mu \mathrm{g} \mathrm{I}^{-1}$ at station 235 (measured below the PBT at 4800 meters depth, Fig. 2). For a flow velocity $u=2 \mathrm{~cm} \mathrm{~s}^{-1}$, this layer must be fed by a resuspension flux of $0.2 \mu \mathrm{g} \mathrm{cm}^{-2} \mathrm{~s}^{-1}$. The corresponding flux per unit surface sediment is proportional to the slope of the rises. For a slope of $10 \%$, the resuspension flux $\phi=0.02 \mu \mathrm{g} \mathrm{cm}^{-2} \mathrm{~s}^{-1}$ is equivalent to $6 \mathrm{mg} \mathrm{cm}^{-2}$ year $^{-1}$. To observe the same concentration with a flow velocity of $10 \mathrm{~cm} \mathrm{~s}^{-1}$, a resuspension flux five times greater is required. This flux value remains largely below the resuspension capacity of a muddy sediment subjected to erosion processes (Southard et al., 1971; Johnson and Johnson, 1970; Hoffert, 1980; Hollister and McCave, 1984; Gardner et al., 1985). This case gives a horizontal transport such as the isopycnal one described for resuspension from the continental shelf (Pak et al., 1980).

ii. Case of soluble particles. The model of random resuspension with depth is applied to calcite particles at the PBT depth. The fact that the calcite layer is mainly found in the PBT is due to the difference between the high mixing inside the PBT layer and the low mixing above and below the PBT (Fig. 9a). The calcium carbonate concentration maxima at the PBT depth is $1 \mu \mathrm{g} \mathrm{kg}^{-1}$ with an uncertainty of $50 \%$, a value which is at least 4 times higher than the ones in the waters out of the PBT layer. The dissolution coefficient $\lambda$ is characterized by a half dissolution time $\tau$ which varies between two months and two years (Honjo and Erez, 1978).

This model requires very high values of the eddy diffusion coefficient in the PBT layer to explain the high calcite concentrations at the PBT depth over the background value, far away from the source. For a theoretical distance from the station to a source of $500 \mathrm{~km}$ and a ratio greater than 4 for the calcite concentrations inside and outside the PBT layer, the model results indicate that the three following conditions should be satisfied together: the $K x$ value must be at least $10^{3} \mathrm{~m}^{2} \mathrm{~s}^{-1}, \tau$ must be less 
than two months and $u$ less than $1 \mathrm{~cm} \mathrm{~s}^{-1}$. If we set a distance to the source of $1000 \mathrm{~km}$, results imply that the constraint on $K x$ remains identical, the maximum velocity $u$ can be of the order of $2 \mathrm{~cm} \mathrm{~s}^{-1}$ and $\tau$ can reach four months. We conclude from these runs that a model with random resuspension along the rise flanks does not seem realistic because it requires simultaneously extreme values of all the three dynamic parameters: $u$ is probably greater than 1 or $2 \mathrm{~cm} \mathrm{~s}^{-1}, \tau$ is certainly larger than two months and the minimum value of $K x$ is the maximum that one can accept.

\section{b. Resuspension at a preferential depth}

The particle sources may occur at specific depths where enough energy is available to induce resuspension. Then, the relative increase of particle concentration at this depth can exist close to the rise flanks (Fig. 9b).

i. Case of insoluble particles. For the insoluble particles, such as the maximum concentrations shown in Figure 2, both this model and the random one apply. Indeed there is no constraints to maintain the rich particle layers in a specific hydrologic environment.

ii. Case of calcite. For a given distance of 500 or $1000 \mathrm{~km}$ from the source to the station, the computed ratio of the calcite concentration at the PBT depth over the background value stays around the value of 4 as found in nature, in the whole range of the possible values of $K x$ and $u$. Therefore, the most probable values of $K x u$ and $\tau$ can apply, and not only the extreme values.

\section{Discussion}

Taking into account the realistic possible values for the main physical parameters, two models only prove applicable:

(a) The "horizontal" advective/diffusive transport model, where the particles are resuspended from rise or seamount flanks, mainly at the PBT depth for calcites. They spread horizontally with current and turbulent mixing along isopycnal surfaces.

(b) The "vertical" settling model where particles come from surface waters by way of fecal pellets or large particles which desegregate at specific depths creating particle "lenses," such as at the PBT depth for calcite.

We can evaluate these two models, using physical, geochemical and sedimentological arguments.

\section{a. Physical arguments}

There are no strong physical constraints which allow us to choose between these two models. Both require high levels of mechanical energy at the depth of maximum 
concentration. In the vertical model, this energy is used for the breakage of the large particles at a preferential depth. In the horizontal model this energy is necessary to resuspend the sediment. Generally the turbulent energy is at a very low level in the water column, due to the vertical stratification of the water. Nevertheless, a great potential of energy is available from the friction of water currents on the flanks of the rises and seamounts and at the boundaries of the water masses at the PBT depth. This energy must be available in the whole PBT area.

For the vertical model, there is no evidence that the available turbulent energy can be transferred at the space scale of the particles' length $(0.1 \mathrm{~mm})$ because the Kolmogorov repartition indicates that energy at this scale is dissipative (Revault d'Allonnes, 1978) and, therefore, cannot be used to break the particles.

With the advective/diffusive model, turbulent energy is fully available for resuspension at any depth. Results of this model indicate that the resuspension of calcites has to occur preferentially at the PBT depth, implying that the threshold of the instantaneous velocity necessary to start the resuspension process is reached more often at the PBT depth than at other depths. This can be explained by internal waves or bursts, generated by the water masses friction, which can induce large increases of the instantaneous flow velocity.

\section{b. Geochemical arguments}

Some of the geochemical data remain ambiguous: in the PBT layer, there is a high proportion of whole coccoliths among calcite debris. Everywhere else this proportion is small. Either a fast settling of particles from the surface waters or a resuspension of sediments rich in coccoliths would yield the same proportion. Nevertheless, geochemical arguments are mainly in favor of the model of horizontal input for the calcites:

- In the deep Pacific, at the PBT depth where we observe the calcite-rich layers, we also find an increase in goethite concentration. These minerals were fully identified (GEOSECS, 1974) using combined techniques involving optical microscopy and scanning electron microscopy (Jedwab, 1980).

- The $\mathrm{Fe} / \mathrm{Al}$ weight ratio measured by instrumental neutron activation on 65 samples in deep pacific waters (GEOSECS, 1974), has a mean value of $3.2 \times$ $10^{2}$ with a quadratic dispersion $\sigma=1.9 \times 10^{2}$. Seven values are greater than $9 \times$ $10^{2}$, six of which are in the PBT layer. The ratio $\mathrm{Fe} / \mathrm{Mn}$, measured with the same technique, on 64 samples in deep Pacific waters has a mean value of 42 with a quadratic dispersion $\sigma=21$. Ten values are greater than 80 , nine of which are in the PBT layer. Thus the high calcite concentrations characteristic of the PBT layer are often associated with particles of goethites typical of volcanic-rich sediments. 


\section{c. Sedimentological arguments}

The horizontal input model for calcites implies that, at the PBT depth, old sediments rich in calcium carbonate exist despite the fact that this depth is largely below the lysocline. Based on DSDP data, calcium carbonate sediments are found on the ridge crest (East Pacific Ridge) where they accumulate. This material continuously drifts down toward the abyssal plain, driven by the plate tectonic drifting. This fraction of the sediments issued from the ridge remains for a time above the lysocline. When moving away from the high productivity zone, the clay fraction of the sediments becomes predominant because of the "en route" dissolution of settling calcites and fully covers calcareous sediments (Hoffert, 1980). When calcareous sediments continuously drift to the deeper depths, they are protected from dissolution by a clay bed, when they pass through the calcite compensation depth and until they reach the PBT depth. Here, after erosion of the clay bed, the calcium carbonate sediment comes in contact with seawater and then calcite resuspension follows (Auger, 1987).

The fact that a possible reservoir of $\mathrm{CaCO}_{3}$ exists is not sufficient to fully assess this horizontal model, the resuspension flux from the bottom sediment should be in agreement with the one computed by the model.

The productive surface of the sea floor is given by the location of the PBT (between $20 \mathrm{~N}$ to $50 \mathrm{~S}$ and between $170 \mathrm{E}$ to $130 \mathrm{~W}$ ), probable flow velocities are on the order of a few $\mathrm{cm} \mathrm{s}^{-1}$ (Craig et al., 1972) and are sufficient for resuspension. Based on the geographic density of rises or seamounts and a mean flank slope of about $10 \%$, a first order approximation for the calcium carbonate flux from the floor to the deep waters, to maintain the observed calcite concentrations at the PBT depth, can be evaluated. This flux ranges from $10^{7}$ to $10^{8}$ tons per year.

- For the horizontal model with random depth resuspension mechanism, the corresponding resuspension rate, for both 500 and $1000 \mathrm{~km}$, is larger than $1 \mathrm{~g} \mathrm{~cm}^{-2}$ year $^{-1}$, which is close to a maximum possible value (Hollister and Mc Cave, 1984).

- For the horizontal model with preferential resuspension at the PBT depth, the corresponding resuspension rate is always below the very reasonable value of $0.5 \mathrm{~g} \mathrm{~cm}^{-2}$ year $^{-1}$. The associated half dissolution time $\tau$ could be greater than six months.

This set of physical, biochemical and sedimentological arguments finally tends to validate the model of calcites transported from rises and seamounts by advective/ diffusive processes at the PBT depth. We do not know if the mechanisms described here are at steady state, if so, the $\mathrm{CaCo}_{3}$ endogenic flux remains active. If the system is not at steady state at geological time scale, this could imply that the sedimentary reservoir involved will be exhausted. We can compute what would happen if the 
calcium carbonate reservoir is not presently supplied. The thickness of the calcium carbonate sediment layer has been evaluated to be of the order of hundreds of meters. That means, for example, that $200 \mathrm{~m}$ of calcite sediments would be able to maintain the computed value of the resuspension rate of $0.5 \mathrm{~g} \mathrm{~cm}^{-2}$ year $^{-1}$ at the PBT depth over a period of one million years.

\section{Conclusion}

The origin and the behavior of the suspended particles in deep Pacific waters, particularly calcite at the PBT depth, were evaluated using simple vertical and horizontal transport models. These models are based on known or assumed physical and geochemical properties.

Mechanical, geochemical and sedimentological arguments supporting the horizontal transport model, involving resuspension and advective/diffusive processes, appear more convincing than the ones for the vertical transport model. This model implies, because of the resuspension process, an input of carbonates from the deep sediment reservoir to the deep ocean system. This input to the Pacific Ocean computed by the proposed model lies between $10^{7}$ and $10^{8}$ tons per year, $\left(10^{9}\right.$ to $10^{10}$ moles per year). This flux implies a resuspension rate of the order of $\mathrm{g} \mathrm{cm}^{-2} \mathrm{year}^{-1}$ from rises and seamounts. If the system is considered at steady state over the geological time scale, this mean value of carbonates input will exist until the sedimentary carbonate stock, from which the suspended particles come, is exhausted.

Acknowledgments. We thank Ann Isley, François Morel and Franklin Coen for their helpful comments and discussions. This is CFR contribution no. 893.

\section{REFERENCES}

Aubey, O. 1976. Contribution à l'étude de la dissolution des particules de carbonate de calcium dans les eaux profondes océaniques. Thèse de spécialité, Université Pierre et Marie Curie, Paris.

Auger, R. 1987. Géochimie et transport des micro-particules de calcite en suspension dans l'Ocean mondial. Doctorat d'Etat es Sciences, $196 \mathrm{pp}$.

Bainbridge, A. E., P. E. Biscaye, W. S. Broecker, R. M. Horowitz, J. L. Sarmiento and D. W. Spencer. 1976. Geosecs Atlantic bottom hydrography, radon and suspended particulate atlas. GOG-NSF.

1977. Geosecs Pacific bottom hydrography, radon and suspended particulate atlas. GOG-NSF.

Berger, W. H. 1967. Foraminiferal ooze: solution at depths. Sciences, 15, 383-385.

Biscaye, P. E. and S. L. Eittreim. 1974. Variations in benthic boundary layer phenomena: nepheloid layer in the North American Basin, in Suspended Solids Water, R. J. Gibbs, ed., Plenum Press, NY.

1977. Suspended particulate loads and transports in the nepheloid layer of the abyssal Atlantic Ocean. Mar. Geol., 23, 155-172. 
Bishop, J. K. B., R. W. Collier, D. R. Ketten and J. M. Edmond. 1980. The chemistry, biology and vertical flux of particulate matter from the upper $1500 \mathrm{~m}$ of Panama Basin in the Equatorial Ocean. Deep-Sea Res., 8A, 615-640.

Bishop, J. K. B. and J. Marra. 1984. Variations in primary production and particulate carbon through the base of the euphotic zone at the site of the Sediment Trap Intercomparison Experiment (Panama Basin). J. Mar. Res., 42, 189-206.

Brewer, P. G., D. W. Spencer, P. E. Biscaye, A. Hanley, P. L. Sachs, C. C. Smith, S. Kadar and J. Fredericks. 1976. The distribution of particulate matter in the Atlantic Ocean. Earth, Planet. Sci. Letts., 32, 393-402.

Brun-Cottan, J. C. 1967. Influence du marquage radioactif sur les paramètres dynamiques des sédiments pélitiques. Thèse de spécialité en océanographie.

- - 1976. Contribution à l'étude de la granulométrie et de la cinétique des particules marines.-Thèse de Doctorat d'Etat, Université Pierre et Marie Curie.

- 1976. Stokes settling and dissolution rate model for marine particles as a function of size distribution. J. Geophys. Res., 81, 1601-1605.

- 1977. Contribution à l'étude de la granulométrie et de la cinétique des particules marines. J. de Recherche Océnographique. 21, 41-54.

- 1986. Vertical transport of particles within the Ocean. NATO-ASI, The role of air-sea exchange in geochemical cycling. Reidel, 83-111.

Carder, K. L., F. Beardsly, and H. Pak. 1971. Particles size distribution in the Eastern Equatorial Pacific. J. Geophy. Res., 76, 5070-5077.

Craig, H., Y. Chung and M. Fiadeiro. 1972. A benthic front in the South Pacific. Earth, Planet. Sci. Letts., 16, 50-65.

Csanady, G. T. 1980. Turbulent Diffusion in the Environment. Geophy. Astrophys. Mono., D. Reidel.

Eittreim, S. L. and M. Ewing. 1976. Turbidity distribution in the deep waters of the Western Atlantic, in Suspended Solids Water, R. J. Gibbs, ed., Plenum Press, NY, 213-225.

Freeland, H. J., P. B. Rhines and T. Rossby. 1975. Statistical observations of the trajectories of neutrally buoyant floats in the North Atlantic. J. Mar. Res., 33, 383-404.

Frenkiel, F. N. 1953. Turbulent diffusion: mean concentration distribution in a flow field of homogeneous turbulence. Adv. Applied Mech., 3, 61-107.

Gardner, W. D., J. B. Southard and C. D. Hollister. 1985. Sedimentation, resuspension and chemistry of particles in the North West Atlantic. Mar. Geol., 65, 199-242.

GEOSECS, Shorebased data report Atlantic II Dec. 1974; GOG-NSF.

GEOSECS, Shorebased data report Pacific II Dec. 1974; GOG-NSF.

Gradshteyn, I. S. and I. M. Ryzhik. 1980. Table of Integrals, Series, and Products. Academic Press.

Harris, J. E. 1972. Characterization of suspended matter in the Gulf of Mexico-1, Spatial distribution of suspended matter. Deep-Sea Res., 19, 719-726.

Hoffert, M. 1980. Les argiles rouges des grands fonds dans le Pacifique Centre Est. Authigénèse, transport et diagénèse. Thèse de Doctorat d'Etat, Univ. Louis Pasteur, Strasbourg, 231 pp.

Hoffmann, E. E., J. M. Klinck and G. A. Paffenhofer. 1981. Concentrations and vertical fluxes of zooplankton fecal pellets on a continental shelf. Mar. Bio., 61, 327-335.

Hollister, C. D. and I. N. Mc Cave. 1984. Sedimentation under deep sea storms. Nature, 309, 220-225.

Honjo, S. 1975. Dissolution of suspended coccoliths in the deep-sea water column and sedimentation of coccolith ooze. Dissolution of Deep-Sea Carbonates. Foraminiferal Res., Spec. Publ. No. 13, 115-128. 
1976. Coccoliths: production, transportation and sedimentation. Mar. Micropaleontology, $1,65-79$.

1978. Sedimentation of materials in the Sargasso Sea at $5367 \mathrm{~m}$ depth deep station. J. Mar. Res., 36, 469-492.

1984. Study of ocean fluxes in time and space by bottom-tethered sediment trap arrays. in Global Ocean Flux Study Workshop, National Research Council, Washington, D.C., 305-324.

Honjo, S. and J. Erez. 1978. Dissolution rate of calcium carbonate in the deep Ocean; an in situ experiment in the North Atlantic Ocean. Earth, Planet. Sci. Letts., 40, 287-300.

Jedwab, J. 1980. Rare anthropogenic and natural particles suspended in deep ocean waters. Earth, Planet. Sci. Lett., 49, 551-564.

Johnson, D. A. 1972. Eastward flowing bottom currents along the Clipperton Fracture zone. Deep-Sea Res, 19, 253-257.

Johnson, D. A. and T. C. Johnson. 1970. Sediment redistribution by bottom currents in the Central Pacific. Deep-Sea Res., 17, 157-169.

Krishnaswami, S., D. Lal, B. L. K. Somajulu, R. Weiss and H. Craig. 1976. Large volume in situ filtration of deep Pacific waters: Mineralogical and radioisotope studies. Earth, Planet. Sci. Letts., 32, 420-429.

Lal, D. 1977. The oceanic microcosm of particles. Science, 198, 977-1009.

Lambert, C., J. K. B. Bishop, P. E. Biscaye and R. Chesselet. 1984. Particulate aluminium, iron and manganese at the deep Atlantic boundary layer. Earth, Planet. Sci. Letts., 70, 237-248.

Lambert, C., C. Jehanno, N. Silverberg, J. C. Brun-Cottan and R. Chesselet. 1981. Lognormal distribution of suspended particles in the Ocean. J. Mar. Res., 39, 77-98.

Mc Cave, I. N. 1975. Vertical flux of particles in the Ocean. Deep-Sea Res., 22, 491-502.

Pak, H., L. A. Codispoti and J. R. V. Zaneveld. 1980. On the intermediate particle maximum associated with oxygen poor water of western South America. Deep-Sea Res., 27, 783-797.

Perigaud C., J. C. Brun-Cottan, P. Biscaye and S. Carson. 1982. Resuspension process of sediment from the bottom in the New-York Bight. EUROMEC 156, The mechanics of sediment transort, 12-14 July 1982.

Riley, G. A. 1963. Organic aggregates in sea water and the dynamic of their formation and utilization. Limnol. Oceanogr., 8, 372-381.

Revault d'Allonnes, M. 1978. Contribution à l'étude de la micro-turbulence au voisinage de l'interface air-mer. Thèse de Doctorat d'Etat de l'Université Pierre et Marie Curie, 289.

Sheldon, R. W., A. Prakash, and S. Sutcliffe. 1972. The size distribution of particles in the Ocean. Limnol. Oceanogr., 17, 327-340.

Southard, J. B., R. A. Young and C. D. Hollister. 1971. Experimental erosion of calcareous ooze. J. Geophys. Res., 76, 5903-5910.

Stommel, H. and A. B. Arons. 1960. On the abyssal circulation of the word ocean. An idealized model of the circulation pattern and amplitude in the oceanic basins. Deep Sea Res., 6, 217-233.

Turner, J. T. 1977. Sinking rates of fecal pellets from the marine copepod pontella meadii. Mar. Biol., 40, 249-259.

Wiebe, P. H., S. H. Boyd and C. Winget. 1976. Particulate matter sinking to the deep-sea floor at $2000 \mathrm{~m}$ in the Tongue of the Ocean, Bahamas, with a description of a new sediment trap. J. Mar. Res., 34, 341-354. 